See Article page 1795.

\section{Commentary: When you wish upon a valve...}

\author{
Gal Levy, MD, and Abe DeAnda, Jr, MD
}

There are few things on which we as cardiovascular surgeons can universally agree, but perhaps 2 would be that all tissue valves will eventually fail and redo valve surgery has increased risks compared with the original procedure. The mechanism of failure may either be structural (ie, stenosis or regurgitation secondary to leaflet degeneration and/or calcification) or nonstructural valve deterioration (ie, infective endocarditis or pannus formation narrowing the outflow or impinging on mechanical valve leaflets). A promising alternative to surgical aortic valve replacement (SAVR) is the use of transcatheter aortic valves (TAVRs) in a valve-in-valve (ViV) configuration to reduce morbidity and mortality of the redo operation. Left unknown is which approach is better, for whom, and for how long.

In this issue of the Journal, the 2 sides of the redo SAVR versus TAVR ViV argument are presented. Clark and Malaisrie $^{1}$ argue that TAVR ViV provides the safest approach to the patient with a failed tissue valve, whereas Greason ${ }^{2}$ argues that redo SAVR fixes the problem.

Let us start with the elephant in the room-patientprosthesis mismatch (PPM). In comparing SAVR versus TAVR ViV with PPM as the outcome of interest, the advantage appears to belong to SAVR. ${ }^{3-5}$ Zorn and colleagues ${ }^{6}$ as well as others have shown that patients with severe PPM are at greater risk for long-term mortality, with smaller surgical valves leading to greater rates of PPM. Greason ${ }^{2}$ reasonably points out that valves smaller than $23 \mathrm{~mm}$ surgically implanted lead down this PPM pathway, noting as well that surgical valve implantation sizes have decreased since 2007, essentially setting the patient up for failure rather than success. Are we failing our surgical patients and

\footnotetext{
From the Division of Cardiovascular and Thoracic Surgery, UTMB-Galveston, Galveston, Tex.

Disclosures: The authors reported no conflicts of interest.

The Journal policy requires editors and reviewers to disclose conflicts of interest and to decline handling or reviewing manuscripts for which they may have a conflict of interest. The editors and reviewers of this article have no conflicts of interest.

Received for publication March 1, 2021; revisions received March 1, 2021; accepted for publication March 2, 2021; available ahead of print March 5, 2021.

Address for reprints: Abe DeAnda, Jr, MD, Division of Cardiovascular and Thoracic Surgery, UTMB-Galveston, 301 University Blvd, Galveston, TX 77551 (E-mail: abdeanda@utmb.edu).

J Thorac Cardiovasc Surg 2022;163:1799-800

$0022-5223 / \$ 36.00$

Copyright (c) 2021 by The American Association for Thoracic Surgery

https://doi.org/10.1016/j.jtcvs.2021.03.004
}

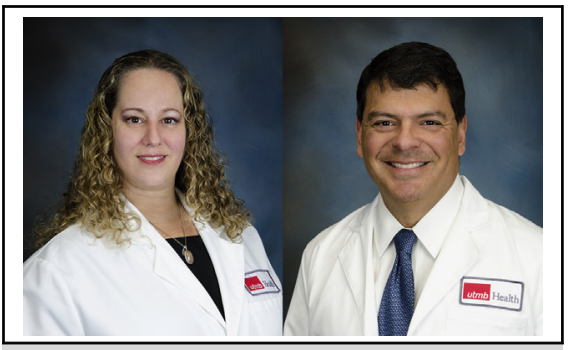

Gal Levy, MD, and Abe DeAnda, Jr, MD

\section{CENTRAL MESSAGE \\ Reoperation for bioprosthetic aortic valve failure can some- times be accomplished with transcatheter techniques, but such approaches are not free of their own issues.}

expecting a ViV to overcome this obstacle? Clark and Malaisrie do mention the PPM problem as a limitation to $\mathrm{ViV}$ and although the valve fracture technique is available, it may not overcome the presence of the original small valve. Even in "normal"-size valves, placing another valve (regardless of the TAVR size) into the existing valve inherently decreases the effective orifice area.

Another risk with ViV TAVR is low coronary anatomy. For patients who are truly not surgical candidates, BASILICA $^{7}$ adds an endovascular option. Lacerating the surgical bioprosthesis to expose the coronary ostium and prevent coronary artery obstruction does come at a cost of increased stroke risk. ${ }^{7,8}$

This commentary is not meant to be an indictment of TAVR ViV. The 2 articles remind us that patients with bioprosthetic valve failure are not all the same, but given that you cannot go back in time, maybe the more correct answer is to provide patients with the optimal valve initially, not relying on limited technology to address projected future downstream issues.

\section{References}

1. Clark A, Malaisrie SC. Failed bioprosthetic valve approaches: transcatheter aortic valve replacement approach. J Thorac Cardiovasc Surg. 2022;163:1795-8.

2. Greason KL. Repeat surgical aortic valve replacement: don't stick a fork in it just yet. J Thorac Cardiovasc Surg. February 4, 2021 [Epub ahead of print].

3. Sá MPB, Van den Eynde J, Simonato M, Cavalcanti LRP, Doulamis IP, Weixler V et al. Valve-in-valve transcatheter aortic valve replacement versus redo surgical aortic valve replacement: an updated meta-analysis. J Am Coll Cardiol Interv. 2021;14:211-20. 
4. Tam DY, Vo TX, Wijeysundera HC, Dvir D, Friedrich JO, Fremes SE. Transcatheter valve-in-valve versus redo surgical aortic valve replacement for the treatment of degenerated bioprosthetic aortic valve: a systematic review and meta-analysis. Catheter Cardiovasc Interv. 2018;92:1404-11.

5. Luthra S, Malvindi PG, Olevano C, Zingale A, Salem H, Ohri SK. Impact of valve size, predicted effective and indexed effective orifice area after aortic valve replacement. J Card Surg. 2021;36:961-8.

6. Zorn GL III, Little SH, Tadros P, Deeb GM, Gleason TG, Heiser J, et al. Prosthesis-patient mismatch in high-risk patients with severe aortic stenosis: a randomized trial of a self-expanding prosthesis. J Thorac Cardiovasc Surg. 2016;151:1014-22.

7. Khan JM, Greenbaum AB, Babaliaros VC, Rogers T, Eng MH, Paone G, et al. The BASILICA trial: prospective multicenter investigation of intentional leaflet laceration to prevent TAVR coronary obstruction. J Am Coll Cardiol Interv. 2019;12: 1240-52.

8. Cohn LH, Aranki SF, Rizzo RJ, Adams DH, Cogswell KA, Kinchla NM, et al. Decrease in operative risk of reoperative valve surgery. Ann Thorac Surg. 1993; $56: 15-21$.
Commentary: Should

valve-in-valve transcatheter aortic valve replacement be first-line treatment for failed aortic bioprostheses?

Jimmy J. H. Kang, BSc, ${ }^{a}$ Derrick Y. Tam, MD, PhD, ${ }^{b}$ and Stephen E. Fremes, MD, MSc ${ }^{\mathrm{b}}$

A recent analysis of the Society of Thoracic Surgeons (STS) Adult Cardiac Surgery Database published in the Journal showed an accelerated decline in mechanical valve use and a simultaneous increase in biological valve use in the aortic position, particularly in patients age $<60$ years. ${ }^{1}$ It is well known that structural valve deterioration is related to 2 key factors-age at the time of implantation and time since implantation ${ }^{2,3}$ - and as such, given the findings from the STS dataset, we can expect to see more patients presenting with a failed bioprosthetic valve needing treatment. Traditionally, bioprosthetic valve failure could be

From the ${ }^{\text {a}}$ Faculty of Medicine and Dentistry, University of Alberta, Edmonton, Alberta, Canada; and ${ }^{\mathrm{b}}$ Division of Cardiac Surgery, Department of Surgery, Schulich Heart Centre, Sunnybrook Health Sciences Centre, University of Toronto, Toronto, Ontario, Canada.

Disclosures: The authors reported no conflicts of interest.

The Journal policy requires editors and reviewers to disclose conflicts of interest and to decline handling or reviewing manuscripts for which they may have a conflict of interest. The editors and reviewers of this article have no conflicts of interest.

Received for publication Jan 14, 2021; revisions received Jan 14, 2021; accepted for publication Jan 15, 2021; available ahead of print Jan 28, 2021.

Address for reprints: Derrick Y. Tam, MD, PhD, Sunnybrook Health Sciences Centre, 2075 Bayview Ave, H408, Toronto, Ontario, Canada M4N3M5 (E-mail: derrick. tam@utoronto.ca).

J Thorac Cardiovasc Surg 2022;163:1800-2

$0022-5223 / \$ 36.00$

Crown Copyright (C) 2021 Published by Elsevier Inc. on behalf of The American Association for Thoracic Surgery

https://doi.org/10.1016/j.jtcvs.2021.01.061

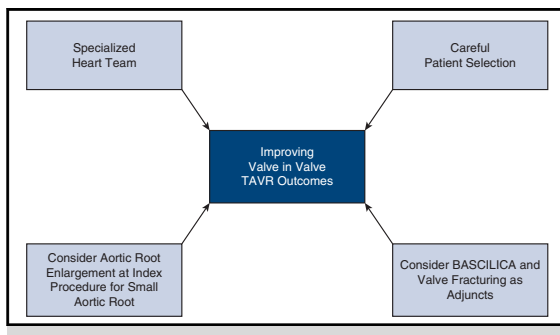

Considerations for improving valve-in-valve transcatheter aortic valve replacement outcomes.

CENTRAL MESSAGE

Valve-in-valve transcatheter

aortic valve replacement has

evolved to become the preferred

approach to managing failed

aortic bioprostheses in selected

patients

treated only with redo surgical aortic valve replacement (SAVR), which is associated with at least double the risk compared with the index procedure. ${ }^{4}$ However, in recent years, transcatheter valve-in-valve $(\mathrm{ViV})$ aortic valve replacement (TAVR) has emerged as a treatment option for failed bioprosthetic valves, despite limited clinical evidence to support its use over redo SAVR. Studies reported before 2020 were small and inadequately powered to detect differences in key clinical outcomes; even a meta-analysis of all available studies at the time included only 498 patients and found improved early morbidity and mortality with ViV TAVR compared with redo SAVR. ${ }^{5}$

However, in 2020, the publication of 3 large series using a combination of administrative and clinical datasets from Canada, ${ }^{6}$ the United States, ${ }^{7}$ and France ${ }^{8}$ confirmed what was observed in previous meta-analyses. Against this backdrop, in this issue of the Journal, Clark and Malaisrie ${ }^{9}$ review the current literature using the ViV TAVR approach 